\title{
Using the modified Delphi method to research the influencing factors of long- term health-related quality of life in patients with unruptured intracranial aneurysms after endovascular treatment
}

Xiao-Dong Zhai ${ }^{1,2 \dagger}$, Chun-Xiu Wang ${ }^{3 \dagger}$, Yong-Jie Ma ${ }^{1,2}$, Jia-Xing Yu ${ }^{1,2}$, Si-Shi Xiang ${ }^{1,2}$, Han-Yi Jiao ${ }^{1,2}$, Peng Shao ${ }^{1,2}$, Xin Guan ${ }^{1,2}$, Jun Wang ${ }^{1,2}$ and Hong-Qi Zhang ${ }^{1,2^{*}}$

\begin{abstract}
Background: The purpose of this study was to use the modified Delphi method to identify the influencing factors of health-related quality of life (HRQoL) in patients with unruptured intracranial aneurysms (UIAs) after endovascular treatment.

Methods: A modified Delphi method to obtain expert consensus on the content of potential influencing factors of HRQoL in patients with UIAs treated by endovascular intervention was employed. The research team consists of three neuroradiologists and one epidemiologist from Xuanwu Hospital of Capital Medical University. They randomly selected 21 well-known experts in cerebrovascular disease diagnosis and treatment as participating experts. The importance of the indicator is based on the 5-Likert scale. The standard deviation (SD), coefficient of variation (CV), mean $(\bar{x})$, and minimum and maximum scores of each indicator were calculated. The consistency was described by Kendall coefficient of concordance with a $p$ value $<0.05$ indicating that the expert consistency was high.

Result: Twenty-one and 18 questionnaires were responded in 2 rounds, with effective response rates of $85.7 \%$ and $100.0 \%$, respectively. The average authoritative coefficient ( $\mathrm{Cr}$ ) of all 21 experts was 0.88 , familiarity with the indicators (Cs) was 0.82 , and the judgment basis of the indicators (Ca) was 0.94 . Eventually, the $\bar{x}$ values of arterial puncture hematoma, hyperlipidemia, gender, marital status, and hospitalization for other diseases were lower than 3.5; CV for marital status and gender was higher than 0.35. The Kendall coefficient of concordance in the first round was $0.19(p<0.001)$, and the second round was $0.15(p<0.001)$.

(Continued on next page)
\end{abstract}

\footnotetext{
* Correspondence: xwzhanghq@163.com

${ }^{+}$Xiao-Dong Zhai and Chun-Xiu Wang contributed equally to this work.

${ }^{1}$ Department of Neurosurgery, Xuanwu Hospital, Capital Medical University,

No. 45 Changchun Street, Xicheng District, Beijing 100053, China

${ }^{2}$ China International Neuroscience Institute (China-INI), Beijing, China

Full list of author information is available at the end of the article
}

C C The Author(s). 2020 Open Access This article is licensed under a Creative Commons Attribution 4.0 International License, which permits use, sharing, adaptation, distribution and reproduction in any medium or format, as long as you give appropriate credit to the original author(s) and the source, provide a link to the Creative Commons licence, and indicate if changes were made. The images or other third party material in this article are included in the article's Creative Commons licence, unless indicated otherwise in a credit line to the material. If material is not included in the article's Creative Commons licence and your intended use is not permitted by statutory regulation or exceeds the permitted use, you will need to obtain permission directly from the copyright holder. To view a copy of this licence, visit http://creativecommons.org/licenses/by/4.0/. The Creative Commons Public Domain Dedication waiver (http://creativecommons.org/publicdomain/zero/1.0/) applies to the data made available in this article, unless otherwise stated in a credit line to the data. 
(Continued from previous page)

Conclusion: In this study, the factors affecting the recovery of HRQoL after endovascular treatment in patients with UIAs were analyzed by the modified Delphi method, which provided a valuable evidence for the clinical management and daily life guidance for UIAs patients.

Keywords: Modified Delphi method, Unruptured intracranial aneurysms, Health-related quality of life

\section{Background}

Advances and increasing availability of high-resolution imaging technologies have led to a higher rate of incidentally detected unruptured intracranial aneurysms (UIAs) $[1,2]$. UIAs are a major public health problem and cause subarachnoid hemorrhage (SAH), intracerebral hemorrhage $(\mathrm{ICH})$, or intraventricular hemorrhage (IVH) when they rupture. The prevalence of UIAs was approximately $7.0 \%$ in Chinese adults aged 35 to 75 years [2]. Health-related quality of life (HRQoL) is regarded as an objective evaluation of physical health, mental health, and social life for patients and is an important component of disease prognosis evaluation methods [3-5]. Previous studies reported that UIA patients who underwent endovascular treatment presented with significant lower HRQoL level than the general population with unknown cause $[3,4,6]$. Therefore, the purpose of this study was to use the modified Delphi method to identify the influencing factors of HRQoL in patients with UIAs after endovascular treatment.

\section{Methods}

\section{Modified Delphi method}

The modified Delphi method can help to fill the knowledge gap by reaching consensus using the knowledge and personal opinions of experts [7, 8]. The modified Delphi method typically presents participants with 2-4 rounds of a fixed set of questions. After each round, participants receive a summary of responses from the previous round. Based on this summary, participants may adjust their answers in the following round. This process continues until participants reach consensus or if no additional consensus is expected [9].

\section{The expert panel}

The research team consists of three neuroradiologists and one epidemiologist from Xuanwu Hospital of Capital Medical University. Participants in modified Delphi method are usually experts on the topic on which the consensus is sought. Their scientific and practical understanding of potential factors and their experience and opinion on whether a factor is major or minor are crucial for Delphi method. There is a general recommendation of 15 to 30 participating experts for a modified Delphi method survey [8]. In addition, geographical spread was also taken into an account to enhance the representativeness of experts. As shown in Table 1, the research team randomly selected 21 experts in cerebrovascular diseases diagnosis and treatment from the national project 2016YFC1300800 as participating experts in the modified Delphi method.

The research team developed the items for the first round of the modified Delphi method based on literature review and expert interview. Combined with the results of the first round of questionnaires and expert opinions, the results after statistical analysis of relevant items are sent to the experts again for a second round of review. The importance of the factors is based on the 5-Likert scale assignment: very important (5 points), important (4 points), normal (3 points), not important (2 points), and very unimportant ( 1 point). The familiarity of experts with the question is assigned from high to low (0.9 to $0.0)$, respectively.

\section{Statistical methods}

Statistical analysis was performed using SPSS Statistics version 24.0 software (IBM Corp., Armonk, New York, USA). The mean $(\bar{x})$, standard deviation (SD), coefficient of variation $(\mathrm{CV})$, and minimum and maximum scores of each indicator are calculated and counted. CV demonstrates the degree of relative concentration among the experts. The Kendall coefficient of concordance was used to describe the degree of consistency of the expert opinions, and the consistency was higher at $p<0.05$.

\section{Results}

\section{Active coefficient of the experts}

The active coefficient of the experts is usually expressed by the response rate of the questionnaire, indicating the concern of the experts on the research of the project. The response rate of the questionnaire which exceeds $70 \%$ is regarded as a higher active coefficient. The study received 21 and 18 questionnaires, respectively, with effective response rates of $85.7 \%$ and $100 \%$, respectively.

\section{Authority coefficient of the experts}

The authoritative coefficient $(\mathrm{Cr})$ is usually determined by two factors: the judgment basis of the indicators $(\mathrm{Ca})$ and the familiarity with the indicator (Cs). The calculation formula is $\mathrm{Cr}=(\mathrm{Ca}+\mathrm{Cs}) / 2$. The value of $\mathrm{Ca}$ and $\mathrm{Cs}$ was obtained mainly through self-evaluation of the experts. The larger the $\mathrm{Cr}$ value, the higher the authoritative coefficient, and $C R \geq 0.7$ is regarded as the high degree of authority 
Table 1 Basic information and authoritative evaluation of 18 experts

\begin{tabular}{|c|c|c|c|c|c|c|c|c|}
\hline Expert ID & Gender & Age (years) & Work years & Degree & Title & $\mathrm{Ca}$ & Cs & $\mathrm{Cr}$ \\
\hline 1 & Male & 48 & 25 & Doctor & Chief physician & 0.9 & 0.9 & 0.9 \\
\hline 2 & Male & 46 & 21 & Doctor & Chief physician & 1 & 0.9 & 0.95 \\
\hline 3 & Male & 56 & 30 & Doctor & Chief physician & 1 & 0.9 & 0.95 \\
\hline 4 & Male & 50 & 26 & Doctor & Chief physician & 1 & 0.9 & 0.95 \\
\hline 5 & Male & 47 & 20 & Doctor & Chief physician & 0.8 & 0.7 & 0.75 \\
\hline 6 & Male & 49 & 26 & Doctor & Chief physician & 0.9 & 0.9 & 0.9 \\
\hline 7 & Male & 46 & 22 & Doctor & Chief physician & 0.9 & 0.9 & 0.9 \\
\hline 8 & Male & 59 & 35 & Bachelor & Chief physician & 1 & 0.9 & 0.95 \\
\hline 9 & Male & 55 & 32 & Bachelor & Chief physician & 0.9 & 0.7 & 0.8 \\
\hline 10 & Male & 42 & 18 & Doctor & $\begin{array}{l}\text { Associate chief } \\
\text { physician }\end{array}$ & 0.9 & 0.7 & 0.8 \\
\hline 11 & Male & 41 & 16 & Doctor & $\begin{array}{l}\text { Associate chief } \\
\text { physician }\end{array}$ & 0.8 & 0.9 & 0.85 \\
\hline 12 & Male & 40 & 10 & Doctor & $\begin{array}{l}\text { Associate chief } \\
\text { physician }\end{array}$ & 1 & 0.9 & 0.95 \\
\hline 13 & Male & 37 & 9 & Doctor & $\begin{array}{l}\text { Associate chief } \\
\text { physician }\end{array}$ & 1 & 0.7 & 0.85 \\
\hline 14 & Male & 40 & 9 & Doctor & $\begin{array}{l}\text { Associate chief } \\
\text { physician }\end{array}$ & 1 & 0.9 & 0.95 \\
\hline 15 & Male & 47 & 22 & Doctor & $\begin{array}{l}\text { Associate chief } \\
\text { physician }\end{array}$ & 0.9 & 0.9 & 0.9 \\
\hline 16 & Female & 50 & 28 & Master & Chief nurse & 1 & 0.7 & 0.85 \\
\hline 17 & Female & 38 & 18 & Bachelor & Supervisor nurse & 1 & 0.7 & 0.85 \\
\hline 18 & Female & 46 & 27 & Bachelor & Supervisor nurse & 0.9 & 0.7 & 0.8 \\
\hline Mean & & & & & & 0.94 & 0.82 & 0.88 \\
\hline
\end{tabular}

coefficient. The average $\mathrm{Ca}$ of all experts was 0.94 (Table 1), and the average Cs was 0.82 . Therefore, the average $\mathrm{Cr}$ of all experts was 0.88 , indicating that the experts included in this study obtained a high degree of authority.

\section{Concentration and coordination of expert opinions}

Calculate the mean $(\bar{x})$ of all indicators after assignment by the 5 -Likert scale. The higher the score, the higher the importance of the indicator. It is considered to be of high importance with a mean score $\geq 3.5$ for each indicator. After the first round of questionnaires, no experts proposed to add a new indicator. The results of the indicators are shown in Table 2. Among them, the arterial puncture hematoma, hyperlipidemia, gender, marital status, and hospitalization for other diseases were less than 3.5 points. A high concentration is indicated by a low value of the $\mathrm{CV}$, and the ideal is $\mathrm{CV} \leq 0.35$ [10]. The $\mathrm{CV}$ of the marital status and gender in this round is higher than 0.35 . So, we excluded the above five indicators that did not meet the criteria for inclusion in the study and included other indicators in the second round of the questionnaire. The Kendall coefficient of concordance represents the consistency of all the experts in the study on the indicators, with $p<0.05$ being statistically significant [11]. The Kendall coefficient of concordance for the first round of study was $0.19(p<0.001)$ (Table 3$)$. In the second round of investigation, the members of the expert group generally believed that the current round of indicators had high reliability and feasibility, and did not propose any additions and deletions of indicators. Therefore, after two rounds of modified Delphi method, we obtained the final indicator system. The second round of research Kendall coefficient of concordance was $0.15(p<0.001)$, which indicates that all the experts reached a high consistency.

\section{The influencing factors screened by modified Delphi method}

As shown in Table 2, indicators screened by the modified Delphi method include aneurysm treatment (intraoperative rupture, residual neck, aneurysm recurrence, rupture during follow-up), treatment-related complications (cerebral infarction), intervention materials (simple coils, stent or balloon-assisted coils, stent or flow diverter), aneurysm characteristics (size, number, location), drug complications (antiplatelet drug, anticoagulant drug), economic status (treatment costs, proportion of treatment costs to 
Table 2 Delphi method results

\begin{tabular}{|c|c|c|c|c|}
\hline Indicators & Mean & Standard deviation (SD) & Median (P25, P75) & $\mathrm{CV}$ \\
\hline Aneurysm treatment & 4.56 & 0.86 & $5(4.5,5)$ & 0.19 \\
\hline Intraoperative rupture & 4.78 & 0.65 & $5(5,5)$ & 0.13 \\
\hline Residual neck & 3.83 & 1.10 & $4(3,5)$ & 0.29 \\
\hline Aneurysm recurrence & 3.94 & 1.11 & $4(3,5)$ & 0.28 \\
\hline Rupture during follow-up & 5.00 & 0.00 & $5(5,5)$ & 0.00 \\
\hline Treatment-related complications & 4.67 & 0.77 & $5(5,5)$ & 0.16 \\
\hline Cerebral infarction & 4.61 & 0.78 & $5(4.75,5)$ & 0.17 \\
\hline Arterial puncture hematoma ${ }^{a}$ & 3.11 & 0.96 & $3(2,4)$ & 0.31 \\
\hline Intervention materials & 4.06 & 0.80 & $4(3,5)$ & 0.20 \\
\hline Simple coils & 3.94 & 0.99 & $4(3,5)$ & 0.25 \\
\hline Stent or balloon-assisted coils & 4.00 & 0.77 & $4(3,5)$ & 0.19 \\
\hline Stent or flow diverter & 3.83 & 0.79 & $4(3,4.25)$ & 0.20 \\
\hline Drug complications & 4.00 & 0.91 & $4(3,5)$ & 0.23 \\
\hline Antiplatelet drug & 3.83 & 1.10 & $3(3,5)$ & 0.29 \\
\hline Anticoagulant drug & 3.56 & 0.98 & $3(3,4.25)$ & 0.28 \\
\hline Aneurysm characteristics & 4.06 & 0.94 & $4(3,5)$ & 0.23 \\
\hline Size & 4.33 & 0.84 & $5(3.75,5)$ & 0.19 \\
\hline Number & 3.89 & 0.96 & $3.5(3,5)$ & 0.25 \\
\hline Location & 4.00 & 0.91 & $4(3,5)$ & 0.23 \\
\hline Economic status & 3.72 & 0.96 & $3(3,5)$ & 0.26 \\
\hline Treatment costs & 3.89 & 0.96 & $3.5(3,5)$ & 0.25 \\
\hline Proportion of treatment costs to household income & 4.11 & 0.96 & $4.5(3,5)$ & 0.23 \\
\hline Source of expenses & 4.33 & 0.91 & $5(3,5)$ & 0.21 \\
\hline Life history & 3.50 & 0.71 & $3(3,4)$ & 0.20 \\
\hline Smoke & 3.89 & 1.02 & $4(3,5)$ & 0.27 \\
\hline Drinking & 3.72 & 1.01 & $4(3,4)$ & 0.27 \\
\hline Sleep time & 3.5 & 1.10 & $4(2,4)$ & 0.31 \\
\hline Physical exercise & 4.00 & 0.91 & $4(3,5)$ & 0.23 \\
\hline Past history & 3.56 & 0.70 & $3.5(3,4)$ & 0.19 \\
\hline Hypertension & 4.28 & 0.89 & $5(3,5)$ & 0.21 \\
\hline Diabetes & 4.00 & 0.97 & $4(3,5)$ & 0.24 \\
\hline Hyperlipidemia $^{a}$ & 3.44 & 0.98 & $3(3,4)$ & 0.29 \\
\hline Heart disease & 3.78 & 0.94 & $3(3,5)$ & 0.25 \\
\hline Mental and psychological factors & 4.33 & 0.77 & $4.5(4,5)$ & 0.18 \\
\hline Anxiety & 4.11 & 0.90 & $4(3,5)$ & 0.22 \\
\hline Depression & 4.06 & 1.06 & $4.5(3,5)$ & 0.26 \\
\hline Demographic information & 3.56 & 0.51 & $4(3,4)$ & 0.14 \\
\hline Gender $^{\mathrm{a}}$ & 3.17 & 1.20 & $3.5(2.75,4)$ & 0.38 \\
\hline Age & 3.72 & 0.96 & $3.5(3,5)$ & 0.26 \\
\hline Education level & 3.78 & 1.11 & $4(3,5)$ & 0.29 \\
\hline Marital status $^{\mathrm{a}}$ & 2.78 & 1.17 & $3(2,4)$ & 0.42 \\
\hline Work ability recovery & 4.28 & 1.18 & $5(3,5)$ & 0.28 \\
\hline mRS change & 4.33 & 0.97 & $5(3,5)$ & 0.22 \\
\hline Diagnosis to treatment time & 3.83 & 0.99 & $3(3,5)$ & 0.26 \\
\hline Follow-up time & 3.61 & 0.78 & $3(3,4)$ & 0.22 \\
\hline Other system complications & 4.11 & 1.08 & $5(3,5)$ & 0.26 \\
\hline Hospitalization for other diseases $^{\mathrm{a}}$ & 3.11 & 0.67 & $3(3,3)$ & 0.22 \\
\hline Family history of cerebrovascular disease & 3.72 & 0.89 & $3(3,5)$ & 0.24 \\
\hline History of cerebrovascular disease & 4.06 & 0.99 & $4.5(3,5)$ & 0.25 \\
\hline
\end{tabular}


Table 3 Kendall coefficients of concordance for two rounds of expert consultation

\begin{tabular}{llll}
\hline Factors & $\begin{array}{l}\text { Kendall coefficients of } \\
\text { concordance }\end{array}$ & $x^{2}$ & $p$ value \\
\hline First round & 0.19 & 167.2 & $<0.001$ \\
Second round & 0.15 & 118.9 & $<0.001$ \\
\hline
\end{tabular}

household income, source of expenses), life history (smoke, drinking, sleep time, physical exercise), past history (hypertension, diabetes, heart disease), mental and psychological factors (anxiety, depression), demographic information (age, educational level, work ability recovery), mRS change, diagnosis to treatment time, follow-up time, other system complications, family history of cerebrovascular disease, and history of cerebrovascular disease.

\section{Discussion}

With the advancement of radiographic technology, the detection rate of UIA patients has increased significantly $[1,2]$. Compared with the general population, the HRQoL level of the UIA patient was significantly lower due to concerns about aneurysm disease, fear of aneurysm rupture, and disease-related symptoms [12]. In recent years, endovascular treatment of UIAs has become a main strategy as result of the superiority over microsurgery clipping in both morbidity and mortality $[13,14]$. Studies reported that the long-term HRQoL levels in patients with UIAs who underwent endovascular treatment have been improved compared with the preoperative [12, 15]. However, even in patients with asymptomatic UIAs, long-term postoperative HRQoL is still significantly lower than the general population [3, 16]. Many UIA patients have not been able to work and study normally after long-term recovery, which greatly affects the quality of life for these patients, considering the high prevalence and the increasing rate of radiographic detection of UIAs in the Chinese population. In addition, with the progress of society and economy, the requirements for quality of life and work ability for UIA patients also increased. Recognizing the underlying factors of poor HRQoL in UIA patients who underwent endovascular treatment and implementing further intervention and guidance from clinical management and daily life for them are essential.

In this research, a modified Delphi method was used to analyze the potential factors affecting postoperative HRQoL recovery in patients with UIAs. We found that in terms of aneurysm treatment, indicators such as treatment outcomes, choice of intervention materials, and treatment-related complications were considered to be important influencing factors. Keeping a healthy lifestyle is vital for UIA patients. Active and effective management of comorbidities such as heart disease, hypertension, and diabetes is essential to improve HRQoL for these patients. The level of education is considered to be an important influencing factor for UIA patients, which may be related to a clear understanding of the aneurysm disease among highly educated people, thus avoiding the excessive psychological burden. The diagnosis to treatment and follow-up time may also lead to differences in HRQoL.

There are certain limitations of the modified Delphi method. It is necessary to use a large sample of clinical cases and multicenter study to analyze the influencing factors screened by the modified Delphi method to obtain more accurate research results. Whatever, it is undeniable that the modified Delphi method has important guiding value for the screening and confirmation of indicators that have not yet reached a consensus.

\section{Conclusion}

In this study, the factors affecting the recovery of HRQoL after endovascular treatment in patients with UIAs were analyzed and confirmed by the modified Delphi method, which provided a valuable evidence for the clinical management and daily life guidance for UIA patients.

\section{Abbreviations \\ Ca: Judgment basis of the indicators; Cr: Authoritative coefficient; Cs: Familiarity with the indicators; CV: Coefficient of variation; HRQoL: Health- related quality of life; IA: Intracranial aneurysm; ICH: Intracerebral hemorrhage; IVH: Intraventricular hemorrhage; mRS: Modified Rankin Scale; SAH: Subarachnoid hemorrhage; UIA: Unruptured intracranial aneurysm}

\section{Acknowledgements}

This research invited 21 experts in the field of cerebrovascular diseases in the 2016 YFC1300800 project. The clinical experience and research ideas of this 21 experts provided important support for this research.

\section{Authors' contributions}

Author contributions to the study and manuscript preparation include the following. All authors contributed to the conception and design. XZ and YM contributed to the acquisition of data. $X Z, C W$, and $Y M$ contributed to the analysis and interpretation of data. $X Z$ and $C W$ contributed to the drafting of the article. All authors contributed to the critical revision of the article. All authors contributed to the reviewing of the submitted version of the manuscript. The authors read and approved the final manuscript.

\section{Funding}

This work was supported by the National Key R\&D program of China with grant 2016YFC1300800 and the Beijing Municipal Administration of Hospitals' Ascent Plan with grant DFL20180801.

\section{Availability of data and materials}

The datasets used and/or analyzed during the current study are available from the corresponding author on reasonable request.

\section{Ethics approval and consent to participate}

This study was a retrospective study. No ethics committee certification is required.

\section{Consent for publication}

Written informed consents were obtained from all patients or their legally authorized representatives, and privacy of patients was effectively protected. 


\section{Author details}

'Department of Neurosurgery, Xuanwu Hospital, Capital Medical University, No. 45 Changchun Street, Xicheng District, Beijing 100053, China. ${ }^{2}$ China International Neuroscience Institute (China-INI), Beijing, China. ${ }^{3}$ Department of Evidence-Based Medicine, Xuanwu Hospital, Capital Medical University, Beijing, China.

Received: 8 October 2019 Accepted: 28 February 2020

Published online: 20 March 2020

\section{References}

1. Vlak MH, Algra A, Brandenburg R, Rinkel GJ. Prevalence of unruptured intracranial aneurysms, with emphasis on sex, age, comorbidity, country, and time period: a systematic review and meta-analysis. Lancet Neurol. 2011;10(7):626-36.

2. Li MH, Chen SW, Li YD, Chen YC, Cheng YS, Hu DJ, Tan HQ, Wu Q, Wang W, Sun ZK, et al. Prevalence of unruptured cerebral aneurysms in Chinese adults aged 35 to 75 years: a cross-sectional study. Ann Intern Med. 2013; 159(8):514-21.

3. Solheim O, Eloqayli H, Muller TB, Unsgaard G. Quality of life after treatment for incidental, unruptured intracranial aneurysms. Acta Neurochir. 2006; 148(8):821-30 discussion 830

4. Young JM, Morgan BR, Misic B, Schweizer TA, Ibrahim GM, Macdonald RL. A partial least-squares analysis of health-related quality-of-life outcomes after aneurysmal subarachnoid hemorrhage. Neurosurgery. 2015;77(6):908-15 discussion 915.

5. Wong GK, Poon WS, Boet R, Chan MT, Gin T, Ng SC, Zee BC. Health-related quality of life after aneurysmal subarachnoid hemorrhage: profile and clinical factors. Neurosurgery. 2011;68(6):1556-61 discussion 1561.

6. Yamashiro S, Nishi T, Koga K, Goto T, Muta D, Kuratsu J, Fujioka S. Postoperative quality of life of patients treated for asymptomatic unruptured intracranial aneurysms. J Neurosurg. 2007;107(6):1086-91.

7. van Vliet DC, van der Meij E, Bouwsma EV, Vonk Noordegraaf $A$, van den Heuvel B, Meijerink WJ, van Baal WM, Huirne JA, Anema JR. A modified Delphi method toward multidisciplinary consensus on functional convalescence recommendations after abdominal surgery. Surg Endosc. 2016:30(12):5583-95.

8. de Villiers MR, de Villiers PJ, Kent AP. The Delphi technique in health sciences education research. Med Teach. 2005;27(7):639-43.

9. Humphrey-Murto S, Varpio L, Wood TJ, Gonsalves C, Ufholz LA, Mascioli K, Wang C, Foth T. The use of the Delphi and other consensus group methods in medical education research: a review. Acad Med. 2017;92(10): 1491-8.

10. Jorm AF. Using the Delphi expert consensus method in mental health research. Aust N Z J Psychiatry. 2015;49(10):887-97.

11. Boulkedid R, Abdoul H, Loustau M, Sibony O, Alberti C. Using and reporting the Delphi method for selecting healthcare quality indicators: a systematic review. PLoS One. 2011;6(6):e20476.

12. Li Y, Dai W, Zhang J. Anxiety, depression and quality of life in patients with a treated or untreated unruptured intracranial aneurysm. J Clin Neurosci. 2017:45:223-6.

13. Zhao J, Lin H, Summers R, Yang M, Cousins BG, Tsui J. Current treatment strategies for intracranial aneurysms: an overview. Angiology. 2018;69(1):1730.

14. Thompson BG, Brown RD Jr, Amin-Hanjani S, Broderick JP, Cockroft KM, Connolly ES Jr, Duckwiler GR, Harris CC, Howard VJ, Johnston SC, et al. Guidelines for the management of patients with unruptured intracranial aneurysms: a guideline for healthcare professionals from the American Heart Association/American Stroke Association. Stroke. 2015;46(8):2368-400.

15. Schwartz C, Pfefferkorn T, Ebrahimi C, Ottomeyer C, Fesl G, Bender A, Straube A, Pfister HW, Heck S, Tonn JC, et al. Long-term neurological outcome and quality of life after World Federation of Neurosurgical Societies grades IV and V aneurysmal subarachnoid hemorrhage in an interdisciplinary treatment concept. Neurosurgery. 2017;80(6):967-74.

16. Buijs JE, Greebe P, Rinkel GJ. Quality of life, anxiety, and depression in patients with an unruptured intracranial aneurysm with or without aneurysm occlusion. Neurosurgery. 2012;70(4):868-72.

\section{Ready to submit your research? Choose BMC and benefit from:}

- fast, convenient online submission

- thorough peer review by experienced researchers in your field

- rapid publication on acceptance

- support for research data, including large and complex data types

- gold Open Access which fosters wider collaboration and increased citations

- maximum visibility for your research: over $100 \mathrm{M}$ website views per year

At BMC, research is always in progress.

Learn more biomedcentral.com/submissions 